\title{
Web-based Expert Decision Support System for Tourism Destination Management in Nigeria
}

\author{
Yekini Nureni Asafe \\ Computer Technology Department \\ Yaba College of Technology \\ Lagos, Nigeria
}

Aigbokhan Edwin Enaholo

Computer Technology Department

Yaba College of Technology

Lagos, Nigeria

\author{
Adetoba Bolaji \\ Computer Technology Department \\ Yaba College of Technology \\ Lagos, Nigeria
}

\author{
Oluwafemi Olubukola \\ Hospitality, Leisure and Tourism Management \\ Yaba College of Technology \\ Lagos, Nigeria
}

\begin{abstract}
The use of Information Technologies have played and currently playing prominent roles in many organizations, such as business, education, commerce. The tourism industry has witnessed the use and application of various computer-based systems in carrying out one or more activities or operation. But currently there is no computer-based system tourist destination to integrate the tourists (from outside Nigeria) and tourists center within Nigeria, so that tourists can make a pre destination plan and decision before venturing into tourism journey to the country Nigeria. The authors of this paper proposed the design of web-based Expert Decision System (WEDSS), to provide tourist to Nigeria and its environ essential data and tools to managing their tours and to base all the decisions concerning to queries on the, tourist centers and hotels based on the following issue; climate, road conditions, cultural aspects, lodging, health facilities, banking, etc. of the location to be visited on sound and rational bases. Web-Based Tourist Decision Support System (WEDSS) for Nigeria will be developed to allow the tourist to find their route in Nigeria and ask for information about sights, accommodations and other places of interest which are nearby to him to improve the convenience, safety, efficiency of travel and enhance tourism attraction of tourists.
\end{abstract}

Keyword-Tourism; Tourism Destination; Decision Support Syste; Web-Based; Lagos; Abuja; Nigeria

\section{INTRODUCTION}

For many countries, either developed or developing, tourism is a very important source of foreign currency earnings and employment. Links between tourists and tourism destination is key success factors for integrated tourism development. Tourism is travel for recreational, leisure, or business purposes. The World Tourism Organization defines tourists as people "traveling to and staying in places outside their usual environment for not more than one consecutive year for leisure, business and other purposes". [1] Tourism has become a popular global leisure activity. In 2011, there were over 983 million international tourist arrivals worldwide, representing a growth of $4.6 \%$ when compared to 940 million in 2010. [2][3]. some kind of traveling have been categorized has tourist travel by international communities.
Theirs possibility that somebody a tourists has never been to the place he or she wish to visit before, and he or she has no relative or friends in the place. For example academician from Canada to present an academic paper in a conference to be held in Lagos Nigeria and there is no available information on geographical location of Nigeria, her economy etc. This person has to decide on how to locate the country Nigeria and available tourist center for leisure, tourist attraction, to sleep overnight etc. The so called tourist has prepared to Visit the country Nigeria for the conference. At a stage he or she has to decide on where to stay, visit and enjoy some tourist attraction within the period of the conference. The successful completion of this stage can be assisted by an Expert Decision Support System (EDSS) developed to analyses the perspectives and planned strategies of this tourism stakeholders.

This paper discusses the model, operation and suitability of a Web-based EDSS for integration of tourist and tourist centers in Nigeria. The paper concludes by assessing the usefulness of the web-based EDSS for tourism planners, and suggests areas for future research.

\section{Objective}

Objective of this study is to design a web-based decision support system for integration of tourists and tourists center within Nigeria, so that tourists can make a pre destination plan and decision before venturing into tourism journey.

\section{Scope of study}

The scope of this study is limited to federal republic of Nigeria

\section{BACKGROUND TO THE STUDY}

The use of ICTs application is a relevant opportunity for growing and strengthening tourism industry, and for the development of destinations economies overall. Specifically ICTs application have the potential to improve destination management [12], [13]: developing and reinforcing local 
tourism and tourism-related entrepreneurship and activities; developing genuine tourism offerings that rely on local productions and traditions (for ex. food, furniture, handicrafts and constructions); enabling direct promotion and commercialization of local tourism offerings in international markets reducing dependence on big foreign intermediaries. Basically ICTs allow destinations to improve online presence (i.e. visibility and participation to Internet market) and offline connectivity (i.e. collaboration, clustering as well as inter sectorial linkages among local public and private tourism and tourism-related actors) required to compete in nowadays global tourism market.

More specifically the beneficial effects of ICTs are to be found in the opportunity to reduce the traditional disadvantages of small operators. First ICTs provide direct, cheap and effective access to (actual and potential) customers. At the same time ICTs make profitable to use multiple distribution channels and target niche markets [10], [13], [14]. Which is almost impossible for SMEs to reach, serve and even to identify?

Tourism in Nigeria centers is largely depends on events, due to the country's ample amount of ethnic groups, but also includes rain forests, savannah, waterfalls, and other natural attractions.[1] The industry, unfortunately, suffers from the country's poor electricity, roads, and water quality.[2] Tourist sites in Nigeria include festivals and cultural celebrations (such as Durbar festivals), the nation's national parks (such as Old Oyo, Yankari, and Cross River National Parks), and other geographical sites (such as Aso Rock, Abuja.)

The tourism industry is regulated by the Ministry of Culture, Tourism and National Orientation, a Nigerian government ministry. [3] In an attempt to raise the profile of the country's tourism sector, a beauty pageant, the Miss Tourism Nigeria Pageant, was created in 2004. [4] The winners in 2004, 2005, and 2006 have been, respectively, Shirley Aghotse,[5] Abigail Longe,[4] and Gloria Zirigbe.[6] The World Travel and Tourism Council estimates revenue related to tourism and travel in Nigeria will exceed 10 billion \$USD in 2007, and will account for approximately $6 \%$ of the gross domestic product.[7]

Tourism in Nigeria has witnessed some development since 1999, when Nigeria transits in to civil rule, The Federal Ministry of Culture and Tourism came into being in June 1999, following the harmonization of the Culture and Tourism as a Ministry by the present Administration. Its creation by a democratic Administration represents an important contribution of the President Olusegun Obasanjo's Administration towards the growth of the Culture and Tourism sub-sector. The vision of the Ministry is to position Culture and Tourism as leverage for economic growth and development in Nigeria. [8]

With the evolution of Internet technologies web-based tools for tour planning can now be easily made available, implemented and become a valuable resource for the traveling community and tourists. Decision Support System provides tools for persuasion and a vocabulary and discipline that facilitate negotiations and coordination across the organizational boundaries. Bousset et al [9]

\section{RESEARCH METHODOLOGY}

Case study area for this research work is Nigeria, a country in Africa continent. This study area was divided into three cardinal point of reference.

Southwest with particular references Lagos State, The choice of Lagos state is based on its relevance in economy development of the country Nigeria, been the former federal capital and economy nerve center of Nigeria and is made up several tourist centers, which includes; Monuments \& Buildings - National Art Theatre, Iganmu, The Remembrance Arcade, Peacock, Lekki Conservation Centre, Lekki Conservation Centre, Lagos Central Mosque, Slave Port, Badagry, Glover Memorial Hall, First Storey Building in Nigeria, Slave Jetty, Badagry, Early Missionary Cemetery, Canon Gun, Instrument of Slave Abolition \& War, Slave Market, Badagry, Christ Cathedral, CMS, Tafawa Balewa Square, Shitta_Bay Mosque etc., Hotels and Restaurant; federal palace hotel, sharaton hotel, aiport hotel etc,

Southeast with particular reference to Anambra state, The choice of Anambra is based on its population as the second most densely populated state in Nigeria after Lagos State, and also some cultural diversity with monumental tourist attraction.

Northern Region with particular reference to Abuja, the federal capital territory. The choice of Abuja is based on its relevance as meeting point of all Nigerians, the seat of power, tourist attraction like zuma rock, and availability of modern hotels and Inns.

\section{Data Collection}

The data for this work come from three sources. Firstly, documentation from Lagos state ministry of tourism from which we gathered data on various tourists' centers and hotels within Lagos State and its environs. Secondly, The Federal Ministry of Culture and Tourism from which we gathered, data on various tourist attractions center within the nook and cranny of the nation. Thirdly, visitation to the 30 selected tourists center (excluded hotels and inn), and forty five hotels (fifteen from each of selected states i.e. Abuja, Lagos and Anambra) to be include in our EDSS database.

\section{Proposed Design Of Wedss}

\section{Description of Proposed System}

Proposed Web-based expert decision support system is a set of computer-based tools; provides tourist with interactive capabilities to enhance his understanding and information basis about considered tourism destination through usage of models and data processing, which in turn allows reaching decisions by combining personal judgment with information provided by these tools.

The proposed web-based EDSS will use artificial intelligence techniques to solve problems, and the architecture will be divided into three levels as shown in figure 2 .

The basic data to be included in the database are the selected data as in tourist centers and hotels obtained from 
data been collected earlier. The proposed system will be designed to give allowances for updating of the database system. The proposed system will be using following technologies; internet based communication tools to enable tourist/s to connect to the system anywhere in the world, email tool that will enable the user to communicate with people

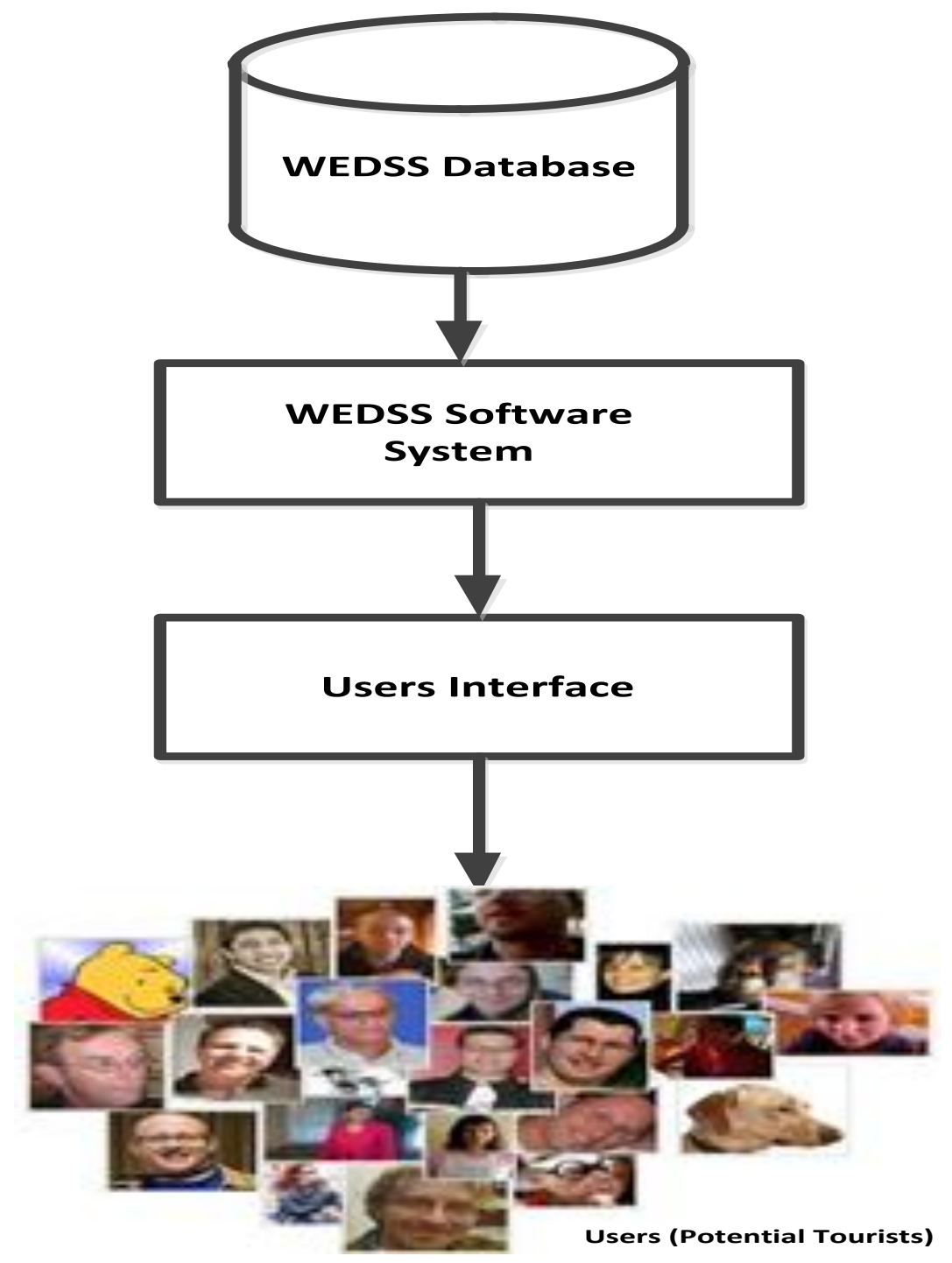

or management of tourist centers. The users (tourists) will communicate with the system via a communication layer as shown in figure 1, figure 2 describe the organization of the proposed WEDSS. The database management system lies on the database server, a server that is isolated in order to avoid hacker's attacks and also provides satisfactory response times.

Fig. 1 Components of WEDSS 


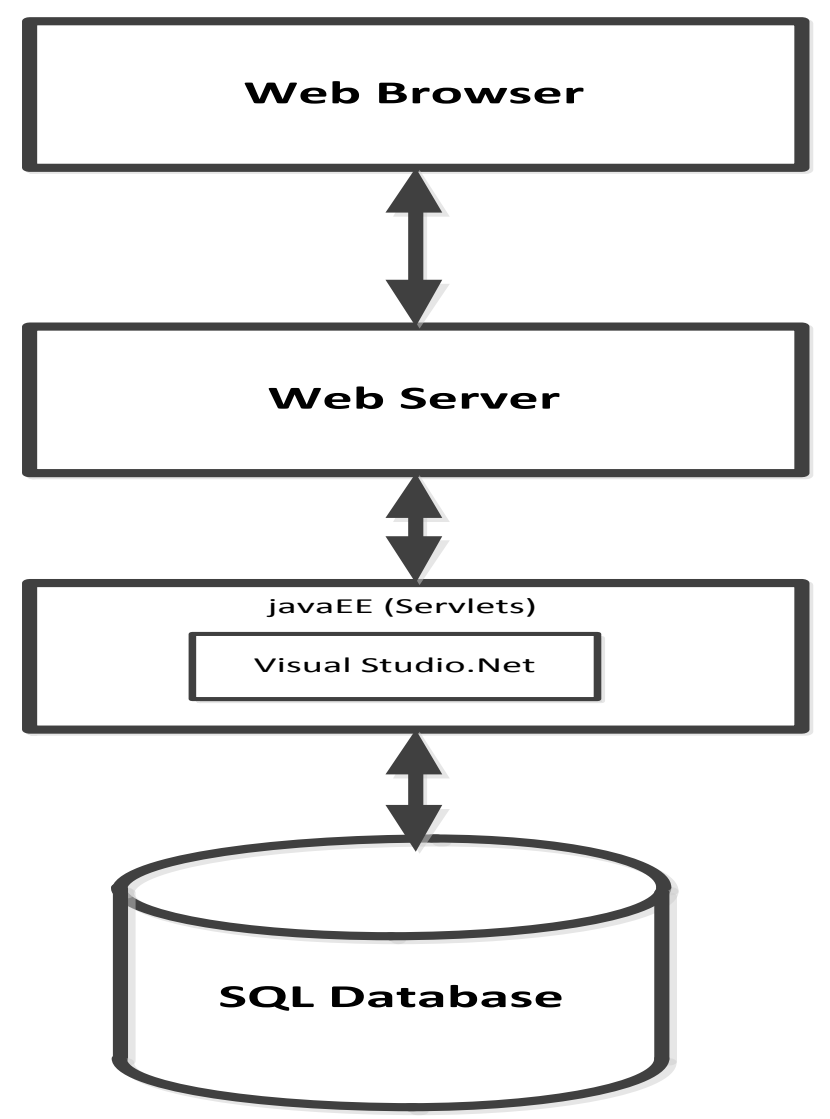

Fig. 2 Organization of WEDSS

Database: The tourism data was gathered under various categories, which constitute various tables in the designed database following a relational database model format. The database will be developed using MySQL

\section{CONCLUSION}

In this study; WTDSS (Web-Based Expert Decision Support System) intended to provide tourism information for tourists visiting the Nigeria will be developed. The development of WEDSS wills has all necessary and required data to publishing on the web. The data will be stored in a data base and contain historical, cultural, geographical, and other relevant data for tourism destination. Since this system is webbased, users (tourists) who has technical possibilities to connect with the Web can have unlimited access to various information required for tourism destination in other to make a decision. The developed WEDSS will provide the tourists vital information to answer the fundamental questions such as near-by facilities, finding route, searching places of interest etc. in Nigeria. Using this kind of system increases convenience and efficiency in tourism activities by providing information for decision support in order to save money, manpower and time.

\section{Advantages of proposed system}

ICTs application are changing significantly the ways in which traditional destination management activities (i.e., Planning, Development, Marketing, Promotion, Delivery,
Management, Coordination and Monitoring of destination's offering) are being carried out.

The same can be said for planning and development as well as for almost all the other destination management activities. So ICTs application can produce a number of benefits for Tourism destination management activities in terms of:

- Enable potential tourists to make pre-plan before embark on tourist.

- Reducing costs, for instance lowering the need to print and distribute promotional material.

- reducing times needed for undertaking activities, for instance the collection and analysis of tourism data, while at the same time increasing their effectiveness (e.g. augmenting periodicity without additional costs).

- increasing quality, for instance with the introduction of authorization processes enabling distributed editing of tourism contents, ensuring up-to-dating as well as precision and truthfulness of information provided;

- increasing effectiveness, for instance through the delivery of targeted promotional campaigns for specific high-value segments or even individuals (using CRM applications) or using web-based learning systems for vocational training, ensuring a wider diffusion of knowledge and competences 


\section{REFERENCES}

[1] Archibong, Maurice (2004-03-18). "Nigeria: Gold mine waiting to be tapped". The Sun Online (The Sun Publishing Ltd.). Retrieved 2012-12-13

[2] Nigeria starts taking tourism sector seriously". afrol.com (afrol News). Retrieved 2013-01-21.

[3] Honourable Minister of Culture, Tourism and National Orientation". UNESCO.org. UNESCO. Retrieved 2012-06-21

[4] Ekunkunbor, Jemi (2012-10-22). "Beauty queens have duties to perform- Barrister Nike Agunbiade". Vanguard online (Vanguard Media Limited). Retrieved 2013-01-11.

[5] Abuja beckons new Miss Tourism Nigeria". The Sun Online (The Sun Publishing Ltd.). 2001-10-05. Retrieved 2007-06-21.

[6] Ekunkunbor, Jemi (2006-12-24). "Winning Miss Tourism is more than an Xmas gift - Gloria Zirigbe". Vanguard online (Vanguard Media Limited). Archived from the original on 2007-01-15. Retrieved 2007-06-21.

[7] Nigeria". Wttc.org. World Travel and Tourism Council. Retrieved 2007-06-21.

[8] http://www.nacd.gov.ng/ministry\%20of\%20culture $\% 20$ and $\% 20$ to urism.htm

[9] Bousset, J. P., Skuras, D., Tesitel, J., Marsat, J. B., Petrou, A., Fiallo-Pantziou, E, Kusova, D. and Bartos, M., "A Decision Support System for Integrated Tourism Development: Rethinking Tourism Policies and Management Strategies", Tourism Geographies, vol. 9(4), 2007, pp. 387-404.

[10] Buhalis, D., "Information technologies as a strategic tool for economic, cultural and environmental benefits enhancement of tourism at destination regions", Progress in Tourism and Hospitality Research, 3(1), 71-93, 1997.

[11] Buhalis, D., eTourism: Information Technology for Strategic Tourism Management. Financial Times/Prentice Hall, London, 2003.

[12] UNCTAD, The Information Economy Report 2005, New York and Geneva, pp. 142-186, 2005
[13] UNWTO, Using Cluster-Based Economic Strategy to Minimize Tourism Leakages, Madrid, 2003

[14] Werthner, H. and Klein, S. Information Technology and Tourism A challenging relationship. Springer-Verlag. Wien-New York, 1999.

\section{AUTHORS PROFILE}

Yekini Nureni Asafe, obtain his academic degree from Lagos State College of education Ijanikin (NCE Physics Education), Lagos State University Ojo (Bsc Computer electronics and engineering), and University of Lagos (Msc Computer Science). He is an academic Staff in the department of computer technology, yaba college of technology, lagos nigeria. He is a member of Nigeria Computer Society (NCS), Member International Association of Engineers (IAENG) and Member International Association of Computer Science and Information Technology (IACSIT)

Adetoba Bolaji, obtain her academic degree from, Obafemi Awolowo University, Ile-ife (Bsc Computer Sciences), University of Lagos (Msc Computer Science), She is an academic Staff in the department of computer technology, yaba college of technology, lagos nigeria. She is currently a researcher in the department of computer science university of Abeokuta Nigeria. She is a member of Nigeria Computer Society (NCS), Computer Proffessional Council (CPN).

Aigbokhan Edwin Enaholo, obtain her academic degree from, University of Benin, (Bsc Computer Sciences), University of Lagos (Msc Computer Science), he is an academic Staff in the department of computer technology, yaba college of technology, lagos nigeria. He is currently a researcher in the department of computer science university of Lagos Nigeria. $\mathrm{He}$ is a member of Nigeria Computer Society (NCS), Computer Proffessional Council (CPN).

Olufemi Olubukola (HND, MRT, TTC), she has a wide experience in hospitality and hotel management. She is currently a principal lecturer in the department of Hospitality Leisure and Tourism Management, Yaba College of Technology, Lagos Nigeria. She is a member of Nigeria Hotel and catering Institute, Hospitality and Tourism Management Association of Nigeria. 